\title{
HUBUNGAN ANTARA KESEIMBANGAN DINAMIS, KOORDINASI \\ MATA-KAKI, DAN POWER OTOT TUNGKAI DENGAN KETEPATAN \\ PASSING PADA PEMAIN PUTRA UMUR10-12 TAHUN KLUB SSB \\ PUTRA ASRI GEMOLONG TAHUN 2020
}

\section{Oleh Ronny Suryo Narbito}

\begin{abstract}
ABSTRAK
Tujuan dari penelitian ini adalah untuk mengetahui:(1) Hubungan AntaraKeseimbangan Dinamis Dengan Ketepatan Passing Pada Pemain Putra Umur 10-12 Tahun Klub SSB Putra Asri Gemolong Tahun 2020.(2) Hubungan AntaraKoordinasi Mata-kaki Dengan Ketepatan Passing Pada Pemain Putra Umur 10-12 Tahun Klub SSB Putra Asri GemolongTahun 2020. (3) Hubungan AntaraPower Otot TungkaiDengan Ketepatan Passing Pada Pemain Putra Umur 10-12 Tahun Klub SSB Putra Asri GemolongTahun 2020. (4) Hubungan Antara Keseimbangan Dinamis, Koordinasi Mata-kaki dan Power Otot TungkaiDengan Ketepatan Passing Pada Pemain Putra Umur 10-12 Tahun Klub SSB Putra Asri GemolongTahun 2020.

Sesuai dengan tujuan penelitian ini, maka penelitian ini menggunakan metode deskriptif dengan pendekatan studi korelasional. Penelitian ini dilaksanakan di Lapangan SSB Putra Asri Gemolong,pada Pemain Putra Umur 10-12 Tahundanpenelitian ini dilaksanakan pada bulan Desembertahun 2019. Dalam penelitian ini variabel bebas disebut juga sebagai prediktor dan variabel terikat yang disebut juga sebagai kriterium. Teknik pengumpulan data dalam penelitian ini adalah menggunakan teknik tes dan pengukuran. Adapun jenis tes yang digunakan adalah: (1) Tes dan pengukuran keseimbangan dinamis dengan modifikasi bass test (Ismaryati, 2008: 51-53). (2) Tes dan pengukuran koordinasi mata kaki dengan soccer wall voley test (Ismaryati, 2011: 54-56). (3) Tes dan pengukuran power otot tungkai dengan standing broad jumptest (Ismaryati, 2008: 64). (4) Tes dan pengukuran ketepatan Passing bola menggunakan petunjuk tes Passing bola diukur dengan tes Passingbola dari Siem Ployer (Soekatamsi, 2000:623).Petunjuk peleksanaan masing-masing tes terlampir.

Berdasarkan analisis data dan pengujian hipotesis yang telah dilakukan, maka simpulan yang dapat diperoleh adalah: (1) Ada hubungan yang signifikanantara Kesimbangan dinamis dengan Ketepatan Passing, $\mathrm{r}_{\text {hitung }}=0.410>$ $\mathrm{r}_{\text {tabel }} \%=0,361$. (2) Ada hubungan yang signifikan antara Koordinasi mata kaki dengan Ketepatan Passing, $r_{\text {hitung }}=0.469>r_{\text {tabel }} \%=0,361$. (3) Ada hubungan yang signifikan antara Power otot tungkai dengan Ketepatan Passing termasuk data inversi karena lebih kecil dari $r$ tabel, $r_{\text {hitung }}=0.493>r_{\text {tabel }} \%=0,361$. (4) Ada hubungan yang signifikan antara Kesimbangan dinamis, Koordinasi mata kaki dan Power otot tungkai dengan Ketepatan Passing, $\mathrm{R}_{\mathrm{y}(123)}^{2}$ sebesar $0.458>\mathrm{r}_{\text {tabel5 } \%}$ pada taraf signifikansi $5 \%$ sebesar 0.361 dan $F_{0}$ sebesar $7.3249>\mathrm{f}_{\text {tabel }}$ pada taraf signifikansi 5\% sebesar 2,89.

Kata kunci : Keseimbangan Dinamis, Koordinasi Mata-kaki, Otot Tungkai dan Passing
\end{abstract}




\section{Hubungan Antara Keseimbangan Dinamis, Koordinasi Mata-Kaki, Dan Power Otot Tungkai Dengan Ketepatan Passing Pada Pemain Putra Umur10-12 Tahun Klub SSB Putra Asri Gemolong Tahun 2020 (Rony Suryo Narbito)}

\section{A. PENDAhuluan}

Perkembangan permainan sepakbola menurut para pakar olahraga dipengaruhi dari berbagai faktor. Terutama dari kualitas permainan dan kekompakan sebuah tim sepakbola. Perkembangan permainan ini menjadikan sepakbola sebagai olahraga fanatic. Permainan sepakbola merupakan olahraga yang bisa dilakukan dan oleh kelompok dari berbagai lapisan masyarakat.

Banyaknya kegunaan yang dapat diperoleh dari permainan ini, baik fisik, mental, maupun sosial. Selain itu juga dengan banyaknya pertandinganpertandingan yang bersifat kompetisi yang secara tidak langsung ikut mempengaruhi dan meningkatkan perkembangan cabang olahraga sepakbola khususnya di tanah air. Untuk dapat bermain sepakbola dengan baik dibutuhkan penguasaan teknik yang baik dan kualitas fisik yang memadai karena meningkatkan keahlian sepakbola hanya akan berhasil jika pemain melatih fisiknya teratur dan berulang kali.

Perlunya pengembangan fisik merupakan salah satu syarat yang sangat dibutuhkan dalam setiap usaha peningkatan prestasi olahragawan. Dalam setiap usaha peningkatan kondisi fisik harus dikembangkan semua komponen yang ada, walaupun dalam pelaksanaan program perlu adanya prioritas untuk menentukan komponen mana yang perlu mendapatkan porsi latihan lebih besar, sesuai dengan olahraga yang ditekuni.

Untuk peningkatan prestasi olahraga sepakbola khususnya pada klub SSB Putra Asri Gemolong diperlukan latihan yang intensif. Pembinaannya meliputi faktor fisik, teknik, taktik dan mental. Selama ini pada latihan yang diberikan lebih menekankan pada faktor teknik. Sedangkan kondisi fisik belum dibina secara maksimal, hal ini bisa disebabkan bahwa faktor fisik dianggap telah terwakili pada saat latihan sehingga kondisi fisik secara otomatis meningkat. Anggapan tersebut kurang benar, karena sepakbola memerlukan unsur kondisi fisik tersendiri sehingga membutuhkan pembinaan fisik yang lebih tepat. Unsur kondisi fisik yang diperlukan pada sepakbola antara lain, power, kekuatan, kecepatan, kelincahan, kelenturan, koordinasi, fleksibilitas, keseimbangan, ketepatan dan daya tahan. 


\section{Hubungan Antara Keseimbangan Dinamis, Koordinasi Mata-Kaki, Dan Power Otot Tungkai Dengan Ketepatan Passing Pada Pemain Putra Umur10-12 Tahun Klub SSB Putra Asri Gemolong Tahun 2020 (Rony Suryo Narbito)}

Pemecahan masalah prestasi olahraga harus ditinjau dari ilmu pengetahuan agar mencapai sasaran tertentu yaitu pencapaian prestasi maksimal. Menurut Mochamad Sajoto (1995: 3-5), prestasi olahraga ditentukan oleh beberapa faktor, diantaranya adalah: (1) faktor biologis, (2) faktor psikologis, (3) faktor lingkungan dan (4) faktor penunjang. Faktor biologis atau fisik yaitu yang berkaitan dengan struktur, postur dan kemampuan biomotorik yang ditentukan secara genetik merupakan salah satu faktor penentu prestasi yang terdiri dari beberapa komponen dasar yaitu: kekuatan (strength), kecepatan (speed), kelentukan (flexibility), kelincahan (agility), daya tahan (endurance), daya ledak (explosive power), keseimbangan (balance), koordinasi (coordination).

Klub SSB Putra Asri Gemolong merupakan salah satu perkumpulan sepakbola yang memiliki kelebihan dan kekurangan dibanding dengan perkumpulan-perkumpulan sepakbola yang lain. Kelebihan-kelebihan tersebut diantaranya adalah memiliki pemain yang rata-rata kompetensi keterampilannya baik, fasilitas olahraga cukup, tetapi prestasi cabang olahraga sepakbola masih rendah atau masih jarang menjadi juara padahal setiap even pertandingan selalu mengikutinya. Pemain kelompok umur 10-12 tahun SSB Putra Asri Gemolong dalam melakukan ketepatan Passing bola sering kurang maksimal sehingga banyak peluang terbuang dalam proses mencetak gol dalam pertandingan.

Ketepatan Passing bola memiliki tingkat kerumitan dan kompleksitas yang berbeda-beda, baik dari keterampilan yang mudah sampai keterampilan yang semakin sulit, dan dari keterampilan yang sederhana sampai pada keterampilan yang kompleks. Dipandang dari tingkat kesulitan dan kompleksitas, ketepatan Passing bola memiliki tingkat kesulitan dan kompleksitas yang tinggi karena mencakup unsur-unsur: koordinasi, timing, tempo, keseimbangan dan akurasi. Ketepatan Passing bola merupakan suatu teknik dasar yang harus dikuasai setiap pemain sepakbola tanpa terkecuali. Ketepatan Passing bola adalah suatu teknik dasar Passing yang sering digunakan oleh setiap pemain untuk menjalankan proses dalam mencetak gol dalam setiap pertandingan. Ketepatan Passing bola dapat dilakukan oleh setiap pemain, biasanya dalam suatu tim sepakbola mempunyai kekompakan tersendiri dalam melakukan Passingbola. Ketepatan 


\section{Hubungan Antara Keseimbangan Dinamis, Koordinasi Mata-Kaki, Dan \\ Power Otot Tungkai Dengan Ketepatan Passing Pada Pemain Putra Umur10-12 Tahun Klub SSB Putra Asri Gemolong Tahun 2020 (Rony Suryo Narbito)}

Passing bola harus dimiliki oleh seorang pemain tanpa terkecuali sebagai modal utama dalam melakukan permainan sampai terjadinya proses gol dalam sepakbola.

Ketepatan Passing bola merupakan salah teknik dasar dalam sepakbola namun cukup sulit dipelajari, lebih-lebih untuk pemain yang belum terampil dan belum terlatih gerak Passing bola secara refleks. Tujuan dalam permainan sepakbola adalah untuk menciptakan proses tembakan yang tepat dan mendapat angka pada setiap kesempatan, yang merupakan syarat tim tersebut dinyatakan pemenang. Dengan demikian keterampilan gerak dasar Passing dalam permainan sepakbola sangat penting untuk dikuasai secara baik, tetapi tidak boleh mengesampingkan keterampilan gerak dasar yang lain. Tingkat keberhasilan pemain memasukkan bola ke gawang dapat dipengaruhi oleh kebiasaan dan penguasaan teknik Passing yang baik, baik Passing pendek maupun Passing jarak jauh.

Pemain SSB Putra Asri Gemolong pada umumnya yang belum menguasai teknik ketepatan Passing bola, merasa belum siap bahkan belum memiliki kekuatan yang memadai, sehingga mengalami kesulitan untuk melakukan ketepatan Passing bola. Kurangnya sarana yang kurang efektif merupakan faktor yang dapat mempengaruhi rendahnya peningkatan ketepatan Passing bola. Selain itu, jarang sekali seorang pelatih maupun pembina menciptakan variasi-variasi latihan yang disesuaikan dengan kondisi dan kemampuan pemainnya. Hal ini sangat penting untuk diperhatikan dalam latihan keterampilan terutama untuk pemain pemula. Kondisi yang tidak memungkinkan untuk latihan dengan sarana yang ada, menuntut pelatih maupun pembina berkreativitas agar tujuan latihan dapat tercapai dengan baik.

Ketepatan Passing bola merupakan teknik dasar yang sulit dipelajari, lebih-lebih untuk pemain yang belum terampil. Agar ketepatan Passing bola dapat dilakukan dengan baik, terlebih dahulu perlu dikaji faktor-faktor yang mempengaruhi ketepatan Passing bola perlu ditelusuri faktor penyebabnya. Dimana faktor-faktor yang mempengaruhi ketepatan paassing bola diperlukan 


\section{Hubungan Antara Keseimbangan Dinamis, Koordinasi Mata-Kaki, Dan \\ Power Otot Tungkai Dengan Ketepatan Passing Pada Pemain Putra Umur10-12 Tahun Klub SSB Putra Asri Gemolong Tahun 2020 (Rony Suryo Narbito)}

unsur-unsur kondisi fisik seperti: kekuatan, kecepatan, kelenturan, keseimbangan, ketepatan, daya tahan, kelincahan, dan koordinasi.

Perbedaan kemampuan terutama terjadi karena kualitas fisik yang berbeda (Sugiyanto, 1997: 353). Kemampuan fisik berhubungan dengan keseimbangan dinamis, dan koordinasi mata-kaki yang mempengaruhi penampilan seseorang baik dalam latihan gerakan-gerakan keterampilan maupun dalam penampilan. Begitu juga dengan power otot tungkai yang mempengaruhi keterampilan pemain. Dengan demikian dapat dikatakan keseimbangan dinamis, koordinasi mata-kaki, dan power otot tungkai adalah suatu persyaratan dalam usaha mencapai prestasi maksimal bagi seseorang dalam latihan ketepatan Passing bola. Keseimbangan dinamis, koordinasi mata-kaki, dan power otot tungkai yang ada pada pemain putra harus menjadi pertimbangan sebagai suatu faktor yang menentukan dalam ketepatan Passing bola yang sesuai dengan karakter dari masing-masing pemain sehingga bisa mencapai hasil latihan yang optimal sesuai dengan potensi yang dimiliki,

\section{B. METODE PENELITIAN}

Metode penelitian yang digunakan adalah metode deskriptif studi korelasional. Dalam hal ini Ali Maksum (2012: 68) berpendapat bahwa "melalui studi korelasional dapat diketahui apakah satu variabel berasosiasi dengan variabel yang lain. Hubungan antara variabel ditentukan dengan menggunakan koefisien yang dihitung dengan teknik analisis statistik". Penelitian ini untuk mengetahui hubungan antara keseimbangan dinamis, koordinasi mata-kaki, dan power otot tungkai dengan ketepatan Passing bola.

\section{HASIL PENELITIAN}

\section{A. Deskripsi Data}

Data yang diperoleh dari tiap-tiap variabel tersebut kemudian dikelompokkan dan dianalisis dengan statistik, seperti terlihat pada lampiran. Adapun rangkuman deskripsi data secara keseluruhan akan disajikan sebagai berikut: 
Hubungan Antara Keseimbangan Dinamis, Koordinasi Mata-Kaki, Dan

Power Otot Tungkai Dengan Ketepatan Passing Pada Pemain Putra

Umur10-12 Tahun Klub SSB Putra Asri Gemolong Tahun 2020 (Rony Suryo

Narbito)

Tabel 1.Deskripsi Data Hasil Tes Kesimbangan dinamis, Koordinasi mata kaki dan Power otot tungkai dan Ketepatan Passing.

\begin{tabular}{|c|c|c|c|c|c|c|}
\hline Variabel & Tes & $\mathrm{N}$ & Mean & SD & $\begin{array}{c}\text { Nilai } \\
\text { Tertinggi }\end{array}$ & $\begin{array}{c}\text { Nilai } \\
\text { Terendah }\end{array}$ \\
\hline $\begin{array}{c}\text { Kesimbangan } \\
\text { dinamis }\end{array}$ & Test & 30 & 85.50 & 6.69 & 96 & 72 \\
\cline { 2 - 7 } & Re-test & 30 & 88.17 & 6.15 & 98 & 78 \\
\hline \multirow{2}{\text{Koordinasimata}}{\begin{tabular}{c} 
kaki \\
\cline { 2 - 7 }
\end{tabular}} & Rest & 30 & 13.93 & 2.52 & 19 & 10 \\
\hline $\begin{array}{c}\text { Power otot } \\
\text { tungkai }\end{array}$ & 30 & 16.53 & 2.47 & 21 & 12 \\
\cline { 2 - 7 } & Rest & 30 & 198.03 & 20.97 & 239 & 158 \\
\hline Ketepatan & 30 & 201.97 & 31.68 & 330 & 158 \\
\cline { 2 - 7 } Passing & Re-test & 30 & 8.80 & 1.58 & 12 & 6 \\
\hline
\end{tabular}

\section{B. Uji Reliabilitas}

Uji reliabilitas bertujuan untuk mengetahui tingkat keajegan hasil tes masing-masing variabel yang dilakukan dalam penelitian. Hasil uji reliabilitas tes dan re-testKesimbangan dinamis, Koordinasi mata kaki dan Power otot tungkai dan Ketepatan Passing kemudian dikategorikan, dengan menggunakan pedoman tabel koefisien korelasi dari Book Walter yang dikutip Mulyono BiyaktoAtmojo (2008:22), yaitu:

Tabel 2. Range Kategori Reliabilitas

\begin{tabular}{|c|c|}
\hline Kategori & Reliabilitas \\
\hline Tinggi Sekali & $0,90-1,00$ \\
\hline Tinggi & $0,80-0,89$ \\
\hline Cukup & $0,60-0,79$ \\
\hline Kurang & $0,40-0,59$ \\
\hline Tidak Signifikan & $0,00-0,39$ \\
\hline
\end{tabular}

Hasil uji reliabilitas data Kesimbangan dinamis, Koordinasi mata kaki dan Power otot tungkai dan Ketepatan Passing pada penelitian ini adalah: 
Hubungan Antara Keseimbangan Dinamis, Koordinasi Mata-Kaki, Dan

Power Otot Tungkai Dengan Ketepatan Passing Pada Pemain Putra

Umur10-12 Tahun Klub SSB Putra Asri Gemolong Tahun 2020 (Rony Suryo

Narbito)

Tabel 3. Ringkasan Hasil Uji Reliabilitas Data

\begin{tabular}{|l|c|c|}
\hline \multicolumn{1}{|c|}{ Variabel } & Reliabilita & Kategori \\
\hline Kesimbangan dinamis & 0.979 & Tinggi Sekali \\
\hline Koordinasi mata kaki & 0.919 & Tinggi Sekali \\
\hline Power otot tungkai & 0.759 & Cukup \\
\hline Ketepatan Passing & 0.772 & Cukup \\
\hline
\end{tabular}

\section{Pengujian Persyaratan Analisis}

Sebelum analisis data dilakukan uji persyaratan analisis. Untuk analisis regresi diperlukan uji persyaratan analisis yaitu normalitas penyebarannilai dan persyaratan linieritas hubungan antara prediktor dengan kriterium. Hasil pengujian persyaratan analisis pada penelitian ini adalah sebagai berikut:

\section{Uji Normalitas}

Uji normalitas data dalam penelitian ini menggunakan chi-kuadrat.

Adapun hasil uji normalitas yang dilPower otot tungkai kan pada hasil tes Kesimbangan dinamis $\left(\mathrm{X}_{1}\right)$, Koordinasi mata kaki $\left(\mathrm{X}_{2}\right)$, Power otot tungkai $\left(\mathrm{X}_{3}\right)$ dan Ketepatan Passing (Y) pada penelitian ini adalah:

Tabel 4. Rangkuman Hasil Uji Normalitas Data

\begin{tabular}{|l|c|c|c|c|c|c|}
\hline \multicolumn{1}{|c|}{ Variabel } & $\mathrm{Db}$ & $\mathrm{M}$ & $\mathrm{SD}$ & $\chi_{\text {hitung }}^{2}$ & $\chi_{\text {tabel 5\% }}^{2}$ & Simpulan \\
\hline $\begin{array}{l}\text { Kesimbangan } \\
\text { dinamis }\end{array}$ & $6-1=5$ & 85.50 & 6.69 & 3.245 & 11,070 & $\begin{array}{c}\text { Berdistribusi } \\
\text { normal }\end{array}$ \\
\hline $\begin{array}{l}\text { Koordinasi } \\
\text { mata kaki }\end{array}$ & $6-1=5$ & 13.93 & 2.52 & 2.358 & 11,070 & $\begin{array}{c}\text { Berdistribusi } \\
\text { normal }\end{array}$ \\
\hline $\begin{array}{l}\text { Power otot } \\
\text { tungkai }\end{array}$ & $6-1=5$ & 198.03 & 20.97 & 1.667 & 11,070 & $\begin{array}{c}\text { Berdistribusi } \\
\text { normal }\end{array}$ \\
\hline $\begin{array}{l}\text { Ketepatan } \\
\text { Passing }\end{array}$ & $6-1=5$ & 7.50 & 1.78 & 2.167 & 11,070 & $\begin{array}{c}\text { Berdistribusi } \\
\text { normal }\end{array}$ \\
\hline
\end{tabular}

Dari hasil uji normalitas yang dilakukan pada tiap-tiap variabel tersebut dapat diketahui bahwa nilai $c h i$-kuadrat yang diperoleh $\left(\chi^{2}\right.$ hitung $)$ pada variabel Kesimbangan dinamis $\left(\mathrm{X}_{1}\right)$, Koordinasi mata kaki $\left(\mathrm{X}_{2}\right)$, Power otot tungkai $\left(\mathrm{X}_{3}\right)$ dan Ketepatan Passing $(\mathrm{Y})$ lebih kecil dari nilai chi-kuadrat 
dalam tabel $\left(\chi_{\text {tabel } 5 \%}^{2}\right)$. Dengan demikian hipotesis nol diterima. Yang berarti bahwa data hasil tes Kesimbangan dinamis $\left(\mathrm{X}_{1}\right)$, Koordinasi mata kaki $\left(\mathrm{X}_{2}\right)$, Power otot tungkai $\left(\mathrm{X}_{3}\right)$ dan Ketepatan Passing (Y) termasuk berdistribusi normal.

\section{Uji Linieritas}

Uji linieritas hubungan antara masing-masing prediktor yaitu Kesimbangan dinamis $\left(\mathrm{X}_{1}\right)$, Koordinasi mata kaki $\left(\mathrm{X}_{2}\right)$, Power otot tungkai $\left(\mathrm{X}_{3}\right)$, dengan kriterium yaitu Ketepatan Passing $(\mathrm{Y})$ dilakukan dengan analisis varians. Rangkuman hasil uji linieritas tersebut dapat dilihat dalam tabel sebagai berikut:

Tabel 5.Rangkuman Hasil Analisis Varians Untuk Uji Linieritas Hubungan Antara Prediktor dengan Kriterium

\begin{tabular}{|c|c|c|c|c|}
\hline Variabel & $\mathrm{db}$ & $\mathrm{F}_{\text {hitung }}$ & $\mathrm{F}_{\text {tabel5\% }}$ & Simpulan \\
\hline $\mathrm{X}_{1} \mathrm{Y}$ & $4: 24$ & 0.56 & 2,78 & Model linier diterima \\
\hline $\mathrm{X}_{2} \mathrm{Y}$ & $13: 15$ & 1.55 & 2,43 & Model linier diterima \\
\hline $\mathrm{X}_{3} \mathrm{Y}$ & $20: 8$ & 1.09 & 3,15 & Model linier diterima \\
\hline
\end{tabular}

Dari rangkuman hasil uji linieritas tersebut dapat diketahui bahwa nilai $\mathrm{F}_{\text {hitung }}$ linieritas yang diperoleh dari tiap variabel lebih kecil dari harga $\mathrm{F}_{\text {tabel }}$ 5\%. Dengan demikian hipotesis nol linieritas ketiga variabel tersebut diterima. Berarti bahwa baik korelasi antara $\mathrm{X}_{1} \mathrm{Y}, \mathrm{X}_{2} \mathrm{Y}$ dan $\mathrm{X}_{3} \mathrm{Y}$ berbentuk linier.

\section{Hasil Analisis Data}

Hasil analisis korelasi dan analisis regresi antara data tes Kesimbangan dinamis $\left(\mathrm{X}_{1}\right)$, Koordinasi mata kaki $\left(\mathrm{X}_{2}\right)$, Power otot tungkai $\left(\mathrm{X}_{3}\right)$ dengan Ketepatan Passing (Y) penelitian ini adalah: 


\section{Hubungan Antara Keseimbangan Dinamis, Koordinasi Mata-Kaki, Dan \\ Power Otot Tungkai Dengan Ketepatan Passing Pada Pemain Putra \\ Umur10-12 Tahun Klub SSB Putra Asri Gemolong Tahun 2020 (Rony Suryo \\ Narbito)}

\section{Analisis Korelasi Tiap Prediktor}

Hasil analisis korelasi masing-masing prediktor dengan kriterium penelitian ini adalah sebagai berikut:

a. Berdasarkan analisis korelasi antara Kesimbangan dinamis $\left(\mathrm{X}_{1}\right)$ dengan Ketepatan Passing (Y), diperoleh koefisien korelasi sebesar 0.410. Dengan $N=30$, nilai $r_{\text {tabel } 5 \%}=0,361$. Ternyata $r_{\text {hitung }}=0.410>r_{\text {tabel } 5 \%}=$ 0,361. Hal ini menunjukkan bahwa terdapat hubungan yang signifikan antara Kesimbangan dinamis $\left(\mathrm{X}_{1}\right)$ dengan Ketepatan Passing (Y).

b. Berdasarkan analisis korelasi antara Koordinasi mata kaki $\left(\mathrm{X}_{2}\right)$ dengan Ketepatan Passing (Y), diperoleh koefisien korelasi sebesar 0.469. Dengan $\mathrm{N}=30$, nilai $\mathrm{r}_{\text {tabel }} \%=0,361$. Ternyata $r_{\text {hitung }}=0.469>r_{\text {tabel } 5 \%}=$ 0,361. Hal ini menunjukkan bahwa terdapat hubungan yang signifikan antara Koordinasi mata kaki $\left(\mathrm{X}_{2}\right)$ dengan Ketepatan Passing (Y).

c. Berdasarkan analisis korelasi antara Power otot tungkai $\left(\mathrm{X}_{3}\right)$ dengan Ketepatan Passing (Y), diperoleh koefisien korelasi sebesar 0.493. Dengan $\mathrm{N}=30$, nilai $\mathrm{r}_{\text {tabel }} \%=0,361$. Ternyata $\mathrm{r}_{\text {hitung }}=0.493>\mathrm{r}_{\text {tabel }} \%=$ 0,361. Hal ini menunjukkan bahwa terdapat hubungan yang signifikan antara Power otot tungkai $\left(\mathrm{X}_{3}\right)$ dengan Ketepatan Passing $(\mathrm{Y})$.

Ringkasan hasil analisis korelasi masing-masing prediktor dengan kriterium penelitian ini adalah sebagai berikut:

Tabel 6. Rangkuman Hasil Analisis Korelasi Tiap Prediktor dengan Kriterium

\begin{tabular}{|c|c|c|c|}
\hline Variabel & $\mathrm{r}_{\text {hitung }}$ & $\mathrm{r}_{\text {tabel }}$ & Simpulan \\
\hline $\mathrm{X}_{1} \mathrm{Y}$ & 0.410 & 0,361 & Korelasi signifikan \\
\hline $\mathrm{X}_{2} \mathrm{Y}$ & 0.469 & 0,361 & Korelasi signifikan \\
\hline $\mathrm{X}_{3} \mathrm{Y}$ & 0.493 & 0,361 & Korelasi signifikan \\
\hline
\end{tabular}

\section{Analisis Regresi}

Analisis regresi yang dilakukan pada penelitian ini menggunakan analisis regresi ganda tiga prediktor. Hasil analisis regresi antara data tes 
Hubungan Antara Keseimbangan Dinamis, Koordinasi Mata-Kaki, Dan

Power Otot Tungkai Dengan Ketepatan Passing Pada Pemain Putra

Umur10-12 Tahun Klub SSB Putra Asri Gemolong Tahun 2020 (Rony Suryo

Narbito)

Power otot tungkai $\left(\mathrm{X}_{1}\right)$, Kesimbangan dinamis $\left(\mathrm{X}_{2}\right)$, Koordinasi mata kaki $\left(\mathrm{X}_{3}\right)$ Power otot tungkai dengan Ketepatan Passing (Y) penelitian ini adalah sebagai berikut:

a. Persamaan garis regresinya adalah:

$\hat{y}=-0.060 X 1+0.087 X 2+-0.001 \quad X 3+11.742$

b. Koefisien korelasi dan determinasi antara prediktor dan kriterium:

$\mathrm{R}_{\mathrm{y}(1,2,3)}=0.676$

$\mathrm{R}_{\mathrm{y}(1,2,3)}^{2}=0.458$

c. Uji signifikansi analisis regresi.

Hasil uji signifikansi regresi penelitian ini dapat dilihat pada tabel berikut:

Tabel 7. Ringkasan Hasil Analisis Regresi

\begin{tabular}{|c|c|c|c|c|}
\hline Sumber Variasi & db & JK & RK & Freg \\
\hline Regresi (reg) & 3 & 41.9114 & 13.9705 & 7.3249 \\
\hline Residu (res) & 26 & 49.5886 & 1.9073 & - \\
\hline Total & 29 & 91.5000 & - & - \\
\hline
\end{tabular}

Dari hasil analisis regresi tersebut dapat disimpulkan, dengan $\mathrm{db}=\mathrm{m}$ lawan $\mathrm{N}-\mathrm{m}-1=3$ lawan 26, harga $\mathrm{F}_{\text {tabel }}$ 5\% adalah 2,89. Sedangkan nilai $\mathrm{F}$ yang diperoleh adalah 7.3249, ternyata lebih besar dari angka batas penolakan hipotesa nol. Dengan demikian hipotesa nol ditolak, yang berarti bahwa terdapat hubungan yang signifikan antara Kesimbangan dinamis $\left(\mathrm{X}_{1}\right)$, Koordinasi mata kaki $\left(\mathrm{X}_{2}\right)$, Power otot tungkai $\left(\mathrm{X}_{3}\right)$ dengan Ketepatan Passing ( $\mathrm{Y}$ ). Adapun besarnya nilai $\mathrm{R}^{2}$ antara Kesimbangan dinamis $\left(\mathrm{X}_{1}\right)$, Koordinasi mata kaki $\left(\mathrm{X}_{2}\right)$, Power otot tungkai $\left(\mathrm{X}_{3}\right)$ dengan Ketepatan Passing (Y) adalah 0.458 . 
Hubungan Antara Keseimbangan Dinamis, Koordinasi Mata-Kaki, Dan

Power Otot Tungkai Dengan Ketepatan Passing Pada Pemain Putra

Umur10-12 Tahun Klub SSB Putra Asri Gemolong Tahun 2020 (Rony Suryo

Narbito)

\section{E. Pengujian Hipotesis dan Pembahasan}

\section{Hubungan Antara Kesimbangan dinamis dengan Ketepatan Passing}

Dari hasil analisis korelasi pada dataKesimbangan dinamis dengan Ketepatan Passing, diperoleh nilai r sebesar 0.410, dimana nilai tersebut lebih besar dari nilai $r_{\text {tabel }}$ pada taraf signifikansi $5 \%$ yaitu 0,361 . Karena nilai $r_{\text {hitung }}>r_{\text {tabel }}$, maka nilai korelasi signifikan. Hal ini berarti bahwaperubahan variansi Ketepatan Passing dipengaruhi oleh komponen variansi Kesimbangan dinamis.

\section{Hubungan Antara Koordinasi mata kaki dengan Ketepatan Passing}

Berdasarkan hasil analisis yang telah dilakukan terhadap data Koordinasi mata kaki terhadap Ketepatan Passing, diperoleh nilai r sebesar 0.469 , dimana nilai tersebut lebih besar dari nilai $r_{\text {tabel }}$ pada taraf signifikansi $5 \%$ yaitu 0,361. Karenanilai $r_{\text {hitung }}>r_{\text {tabel }}$, maka nilai korelasi signifikan. Hal ini berarti bahwa variansi unsur Koordinasi mata kaki berpengaruh terhadap peningkatan variansi Ketepatan Passing.

\section{Hubungan Antara Power otot tungkai dengan Ketepatan Passing}

Berdasarkan hasil analisis yang telah dilakukan terhadap data Power otot tungkai terhadap Ketepatan Passing, diperoleh nilai r sebesar 0.493, dimana nilai tersebut lebih besar dari nilai $r_{\text {tabel }}$ pada taraf signifikansi $5 \%$ yaitu 0,361. Karenanilai $r_{\text {hitung }}<r_{\text {tabel}}$, maka nilai korelasi signifikan. Dengan demikian dapat disimpulkan bahwa Power otot tungkai memiliki hubungan yang signifikan terhadap Ketepatan Passing.

4. Hubungan Kesimbangan dinamis, Koordinasi mata kaki dan Power otot tungkai dengan Ketepatan Passing

Pada Hipotesis dinyatakan bahwa hubungan antara Kesimbangan dinamis, Koordinasi mata kaki dan Power otot tungkai dengan Ketepatan Passing di ketahui $\mathrm{R}_{\mathrm{y}(123)}^{2}=0.458$ sedangkan $\mathrm{r}_{\text {tabel }}$ pada taraf signifikasi 0,05 dan $\mathrm{n}=30$ di dapat $\mathrm{r}_{\text {tabel }}=0,361$, dengan hasil tersebut $\mathrm{r}_{\text {hitung }}>\mathrm{r}_{\text {tabel5 }} \%$ dan

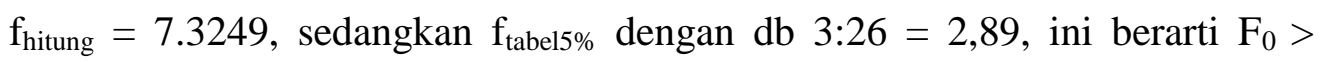
$\mathrm{F}_{\text {tabel5\% }}$ Maka hipotesis di terima. 


\section{Hubungan Antara Keseimbangan Dinamis, Koordinasi Mata-Kaki, Dan \\ Power Otot Tungkai Dengan Ketepatan Passing Pada Pemain Putra Umur10-12 Tahun Klub SSB Putra Asri Gemolong Tahun 2020 (Rony Suryo Narbito)}

\section{SIMPULAN}

Berdasarkan hasil penelitian dan hasil analisis regresi dan korelasi product moment yang telah dilPower otot tungkai kan dapat diperoleh simpulan sebagai berikut:

1. Ada hubungan yang signifikan antara Kesimbangan dinamis dengan Ketepatan Passing, rhitung $=0.410>$ rtabel $5 \%=0,361$.

2. Ada hubungan yang signifikan antara Koordinasi mata kaki dengan Ketepatan Passing, rhitung $=0.469>$ rtabel $5 \%=0,361$.

3. Ada hubungan yang signifikan antara Power otot tungkai dengan Ketepatan Passing termasuk data inversi karena lebih kecil dari $r$ tabel, rhitung $=0.493>$ rtabel $5 \%=0,361$.

4. Ada hubungan yang signifikan antara Kesimbangan dinamis, Koordinasi mata kaki dan Power otot tungkai dengan Ketepatan Passing, R2y(123) sebesar $0.458>$ rtabel5 \% pada taraf signifikansi 5\% sebesar 0.361 dan F0 sebesar $7.3249>$ ftabel pada taraf signifikansi $5 \%$ sebesar 2,89.

\section{DAFTAR PUSTAKA}

Agus Mahendra. 2007. Teori Belajar Mengajar Motorik. Bandung: Universitas.

Ali Maksum. 2012. Metodologi Penelitiandalam Olahraga. Surabaya: UnesaUniversity Press

Beautelstahl, Dieter. 2007. Belajar Bermain Bola Volley. Bandung: Pionir Jaya.

Eric Batty C. 2003. Latihan Sepakbola Metode Baru. Serangan, Bandung: Pionet.

Harsono. 2011. Latihan Kondisi Fisik. Bandung. Universitas Pendidikan Indonesia.

Imam Imanudin. 2008. Ilmu Kepelatihan Olahraga. Bandung: Universitas Pendidikan Indonesia.

Ismaryati. 2006. Tes dan Pengukuran Olahraga. Wonogiri: UNS Press. 